\title{
Bullying and social anxiety experiences in university learning situations
}

\author{
Maili Pörhölä ${ }^{1}$ D $\cdot$ Merja Almonkari' ${ }^{2}$ Kristina Kunttu ${ }^{3}$
}

Received: 16 April 2018 / Accepted: 22 April 2019 / Published online: 21 May 2019

(C) The Author(s) 2019

\begin{abstract}
This study examines how individuals' engagement in bullying at school and at university relates to the anxiety they feel in general and in various learning situations in which students interact during their higher education. It was predicted that, of the individuals who have experiences of bullying (in the role of bully, victim, or in a dual role as bully-victim), those who have been subjected to bullying experience more anxiety than do those who have no experience with bullying. A nationally representative sample of Finnish university students $(N=5086)$ participated in the study by responding to survey questions assessing their experiences of (a) anxiety syndrome, (b) context-specific social anxiety, and (c) situation-specific social anxiety in university learning settings. The findings revealed that victims differed from those with no experience of bullying in that they reported more of having current diagnosis of anxiety syndrome and higher levels of context-specific social anxiety in university learning contexts. This held true for both victims of school bullying and those who were bullied at university. The particular learning situations in which victims reported significantly higher levels of social anxiety were seminars, discussions with their teacher, and taking tests and exams. Implications for educational practices at university, student health services, and future directions for research are discussed.
\end{abstract}

Keywords Bullying $\cdot$ Higher education · Learning situation · Social anxiety · University student $\cdot$ Victimization

Maili Pörhölä

maili.porhola@gmail.com

Merja Almonkari

malmonkari@gmail.com

Kristina Kunttu

kristina.kunttu@historia-memoria.fi

1 University of Eastern Finland, Joensuu, Finland

2 University of Jyväskylä, Jyväskylä, Finland

3 Finnish Student Health Service, Turku, Finland 


\section{Introduction}

Interaction is one of the salient means of learning in educational contexts such as university. In order to learn together, students interact with each other and their teachers in various learning situations. These include sharing understanding and knowledge; creating, presenting and evaluating ideas; giving and receiving feedback; negotiating and arguing; and expressing agreement and disagreement with other participants of the interaction. In many countries, such as Finland where the present study was conducted, there has been a transition from teacher-centered and content-oriented instruction to more student-centered and learning-oriented educational practices. Instead of seeing students as silent listeners of mass lectures, they are now perceived as actors who are actively constructing their knowledge and understanding, significant agents of their own learning; the role of teachers is seen to be as supporters for student participation and interaction (Parpala and LindblomYlänne 2007).

These pedagogical principles increase the significance of interaction in learning situations. However, as Keashly and Wajngurt (2016) note, features of academia also promote an environment at university in which ideas are subjected to rigorous scrutiny and critique, and, in such an environment, dissent and disagreement are valued and expressed through vibrant debate and dialogue. Ideas flow and are challenged, while expertise and authority are invoked and also challenged. What is permitted and promoted in academic discussion may be experienced in other social contexts as inappropriate and even abusive behavior. The content and tone of the discussion, for example, critique given or received can also vary between individual students. Although this interaction can be seen as rewarding and supportive by some students, in some of them it might generate distress and anxiety and even feelings of being abused and bullied.

Indeed, some students experience high levels of social anxiety in university learning situations (Almonkari 2007; Almonkari and Kunttu 2012; Kunttu and Huttunen 2009; Russell and Shaw 2009; Topham and Russell 2012). The Diagnostic and Statistical Manual of Mental Disorders of the American Psychiatric Association (DSM-5 2013) defines social anxiety as "a persistent fear of one or more social or performance situations in which the person is exposed to unfamiliar people or to possible scrutiny by others." While some people feel social anxiety constantly in a range of different social situations (i.e., generalized social anxiety), for others the fear is circumscribed and evoked only in a specific context (i.e., specific social anxiety), and often preceded by specific traumatic experiences (Rachman 2013). Some students can also suffer from an anxiety syndrome, which refers to a recurring disorder that can be but is not necessarily related to any social context (e.g., panic disorder).

Russell and Shaw (2009) argue that social anxiety is likely to have an inhibitory effect on social interaction and a student's ability to perform well and interact effectively in learning settings that require social interaction and the confidence to express oneself. In addition to hampering or delaying learning, the distress and anxiety caused by social interaction can make learning situations uncomfortable 
for some students and decrease their study motivation. In order to be able to provide support to these students and ease their feelings of anxiety, it is important to identify individual students and student groups who suffer from social anxiety in university learning situations and understand the origins of their anxiety, as well as be aware of the kind of learning situations which are experienced by them as being the most anxiety-inducing.

A group of students who can be at a heightened risk for suffering of social anxiety in university learning situations are those who have been subjected to bullying by peers in educational contexts, either previously during their school days or currently at university. Significant associations have already been found between generalized (social) anxiety and bullying victimization in childhood and adolescence (e.g., Bond et al. 2001; Gómez-Ortiz et al. 2017; Pabian and Vandebosch 2016; Reijntjes et al. 2010; Stapinski et al. 2015; Storch et al. 2003; Storch and Masia-Warner 2004).

It is not clearly understood how long the exposure to bullying impacts an individual. For example, the meta-analysis of 18 longitudinal studies conducted by Reijntjes et al. (2010) found significant associations over time between peer victimization and internalizing problems, including anxiety, among primarily middle school students. Some studies have suggested that some victims of school bullying continue to suffer from anxiety as young adults. For example, the studies by Espelage et al. (2016), and Newman et al. (2005) among college students revealed significant associations between previous experiences of peer victimization at school and current symptoms, including anxiety. Similarly, Copeland et al. (2013) found that peer victimization in childhood and adolescence was associated with generalized anxiety and panic disorder still as adult, and the study by Lereya et al. (2015) showed that young adults who had been bullied by peers as children were even more likely to have mental health problems, including anxiety, than were those who had been maltreated by adults in childhood.

Studies which have established associations between bullying victimization and (social) anxiety, however, have examined anxiety mainly as a characteristic feature or syndrome that is generalized across a wide range of social contexts and situations, and the terms used for this phenomenon have varied from "social anxiety" to "anxiety" and "anxiety disorders" (see, e.g., Bond et al. 2001; Copeland et al. 2013; Espelage et al. 2016; Gómez-Ortiz et al. 2017; Lereya et al. 2015; Newman et al. 2005; Pabian and Vandebosch 2016; Storch et al. 2003; Storch and Masia-Warner 2004; Stapinski et al. 2015). Although the association between bullying victimization and generalized (social) anxiety/anxiety syndrome has been well demonstrated in the above mentioned studies, there is less evidence of the possible relationship between bullying victimization and specific social anxiety that is experienced in various learning situations. One could presume that, compared with students with no previous or concurrent experiences of bullying victimization, students who have been victimized by peers would display not only higher levels of generalized (social) anxiety but also more social anxiety in the kinds of interaction situations in which the bullying has occurred, such as learning situations in educational contexts. Giving support to this assumption, Almonkari and Kunttu (2012) found that among those students who reported that social anxiety in university learning situations was 
a substantial problem for them, $25 \%$ of males and $20 \%$ of females had experienced bullying victimization for several years during their school days.

Getting better knowledge of the characteristics and origins of the anxiety they feel in learning situations in university could help the victims of bullying better understand their own responses and cope with them. This kind of understanding can also be used to guide university staff members in developing a social climate and learning environments that would reduce the anxiety felt by these students and, in this way, improve their learning ability.

In this study, we examine whether previous and current experiences of peer victimization are associated with having an anxiety syndrome and, in particular, with the social anxiety that the student experiences in university learning contexts, and if they do, which learning situations differentiate victims from others. A nationally representative sample of young adult students in Finnish universities completed surveys that asked them to report on experiences of bullying in school and at university, and gathered information regarding their psychosocial and physical well-being, including reports on social anxiety and anxiety syndrome.

\subsection{Social anxiety and learning situations in university}

Typical of socially anxious individuals is a fear that they will act in a way (or show anxiety symptoms) that will be embarrassing and humiliating. Although they recognize that their fear is unreasonable or excessive, they tend to avoid the feared situations or else are faced with intense anxiety and distress. The avoidance, anxious anticipation, or distress in the feared social or performance situations interferes significantly with the persons' normal routine, occupational or academic functioning, or social activities or relationships (DSM-5 2013).

Social anxiety is seen to arise from the prospect or presence of interpersonal evaluation in real or imagined social situations (Schlenker and Leary 1982), and it can manifest on multiple levels, including physiological (e.g., increased heart rate and muscle tension, sweating, trembling), cognitive (e.g., negative expectations and selfevaluations), affective (e.g., fear, anxiety), and behavioral (e.g., lack of fluency and attentiveness). The results can include, among others, an inability to write in public, or a reluctance to speak with other people. Social anxiety tends to emerge in adolescence or early adulthood (Rachman 2013).

The cognitive theory of social anxiety (e.g., Clark and Wells 1995) can be applied to help understand how cognitive and interpretive biases that operate in social anxiety affect the behavioral choices socially anxious individuals tend to make in social events such as learning situations in university. This theory assumes that socially anxious people have a strong tendency to overpredict the probability and the seriousness of aversive social situations, being prone to information-processing biases in these situations. They tend to interpret social situations in a threatening manner due to the distorted assumptions they make about interaction, themselves, and the ways in which they should behave in these situations. Having unreasonably high standards for their own social behavior, they make negative self-evaluations and anticipate corresponding perceptions of their behavior by others. When they enter 
a demanding social situation, they begin to experience high levels of autonomic arousal, the sensations of which (e.g., increased heart rate, trembling hands) interfere with their ability to process the ongoing interaction. As the result, their negative self-evaluations are triggered, confirming their anticipation of the inadequacy and unacceptability of their behavior. In an attempt to reduce the risk of being negatively perceived by others, socially anxious people tend to engage in safety behavior, such as avoidance of being initiative in social interaction or avoidance of social situations as much as possible. Behavioral choices they therefore make can be interpreted as a display of disinterest or even non-friendly, which elicits corresponding behavior from their interaction partners to further confirm their fears that other people disapprove them.

The distress, negative expectations, and avoidance behavior provoked in university learning situations can hamper socially anxious students' learning and study success. For example, Topham and Russell (2012) suggest that these students can miss out on many learning opportunities because they tend to focus on their anxiety and avoid interaction. Therefore, their study success can be lower than they wish it was or believe it should be, which might cause further anxiety in various kinds of learning situations.

In Finland, specific social anxiety evoked in university learning contexts was experienced as a substantial problem by $17 \%$ of female and $11 \%$ of male university students and as a mild problem by $39 \%$ of female and $36 \%$ of male students (Almonkari and Kunttu 2012). Learning situations in which students experienced the highest frequencies of social anxiety were, in descending order, talking to an audience, academic seminar discussions, and speaking foreign languages. Situations in which social anxiety was reported less frequently included talking with a teacher and taking written exams. In comparison, in the United Kingdom, Russell and Shaw (2009) found that approximately $10 \%$ of students reported marked to severe social anxiety in learning situations at university. Situations in which the highest frequencies of "severe fear" were reported were, in descending order, talking to a large audience, taking written tests, giving a report to a small group, and speaking up in a meeting. In another study in the United Kingdom, Russell and Topham (2012) found that, again, the highest number of students reported frequent experiences of social anxiety when giving presentations, followed by participating in seminars, in group work, attending lectures, and finally when sharing IT facilities in education.

In a study by Almonkari (2007), 54\% of students who reported feelings of social anxiety in learning situations at university interpreted that their fear originated in previous experiences of being bullied by peers, and a study by Almonkari and Kunttu (2012) further suggests an association between bullying victimization and specific social anxiety experiences in university learning contexts. Indeed, characteristic features of bullying victims include a tendency to anticipate negative evaluation (Storch et al. 2003; Storch and Masia-Warner 2004), and a lowered self-esteem (Arseneault et al. 2010; Juvonen et al. 2000). The victims also tend to suffer from long-term generalized social anxiety (Copeland et al. 2013; Lereya et al. 2015; Newman et al. 2005). The accumulation of social anxiety and bullying experiences in the same individuals can further increase the distress they feel in university learning situations. 


\subsection{Experiences of bullying and learning situations in university}

There is no consensus among researchers on how bullying in a higher education context should be defined, and consequently, definitions and measures used to assess the phenomenon have varied between studies. The definitions given to bullying arise from either school or workplace context, and stress three components of the phenomenon: (a) the target person is exposed to aggressive behaviors or intentional/ goal-directed doing of harm by the perpetrators; (b) this harm-doing is carried out repeatedly; (c) the target person is somewhat helpless against the perpetrators due to the existing power imbalance between them (e.g., Olweus 1993; Volk et al. 2014). These components have been found to be widely adopted as criteria for bullying in different contexts (Gladden et al. 2014; Menesini and Salmivalli 2017; Pörhölä et al. 2006; Volk et al. 2014), and they were used in the present study for the definition given to the respondents.

Existing research conducted in different countries has indicated that the most typical forms of bullying at university are verbal (e.g., inappropriate, nasty, rude, or hostile comments; name calling; mocking or criticism related to personal qualities) and relational (e.g., social exclusion; spreading of malicious rumors or gossip; damage caused to peer relationships). However, cyberbullying by means of communication technology and physical forms of bullying are less often reported (e.g., Giovazolias and Malikiosi-Loizos 2016; Lund and Ross 2016; Matsunaga 2010; Pörhölä et al. 2016; Wensley and Campbell 2012). While the measures used to assess bullying have notably varied between studies, those studies which have included assessment of study-related or academic forms of bullying (e.g., humiliation or ridicule in connection with studies; hints of being incompetent; ignoring comments; withholding of information; ignoring requests for help) suggest that this kind of bullying is often experienced by students during higher education (Cooper et al. 2011; Marraccini et al. 2015; Pörhölä et al. 2016; Rospenda et al. 2013). For example, in a study by Pörhölä et al. (2016) among approximately 8500 university students in four countries (Argentina, Estonia, Finland, and the United States), the most often reported form of bullying victimization in all countries was unjustified criticism, belittling or humiliation related to studies, the number of students reporting these experiences varying from 11.5 to $14 \%$ between countries. This was followed by verbal attacks, mocking or criticism related to personal qualities, and damage to peer relationships or social discrimination.

These findings suggest that some characteristics of academic interaction, such as evaluation and critique and challenging of ideas can sometimes be presented in such a form that they are felt to be intimidating and hurtful by some students. The critique given can be harsher and more negative to some students who might even feel they are being bullied. Due to having previous experiences of peer victimization at school, some students could also be more sensitive to evaluation and tend to interpret the critique they receive as bullying. If these students are repeatedly subjected to evaluation they experience as negative in learning contexts, they might start to feel social anxiety particularly in learning situations that provide an opportunity for criticizing an individual student's skills, knowledge, performance, and even personal characteristics. 
Furthermore, while studies exist to show that being bullied by peers is associated with academic problems and deficiencies in academic achievements in childhood and adolescence (Espelage et al. 2013; Glew et al. 2005; Houbre et al. 2006; Juvonen et al. 2011; Perren et al. 2010; Strøm et al. 2013), this association may fall away as students grow up. In the 5-year longitudinal study which examined the effects of middle school bullying and victimization through high school, Feldman et al. (2014) found that victimization was unrelated to academic achievement (i.e., the average grade a student received in all subjects attempted for any given year), and school attendance concurrently and over time when controlling for simultaneous bullying behavior. Similarly, Holt et al. (2014) found that past bullying experiences were not associated with academic performance in college. Finally, a nationally representative survey with data from approximately 4400 students in Finnish universities indicated that students who were bullied by their fellow students in university did not differ from those uninvolved in bullying in the credits they earned per year, even though they were more exhausted and less satisfied with their academic achievements than students uninvolved in bullying (Saarinen 2016).

These findings suggest that bullying victims at university could be individuals who are very focused on their studies and have high expectations for their study success, and therefore they might be particularly sensitive to the feedback and critique they receive of their study performances. This could further increase the distress and social anxiety they feel in learning situations that include evaluation. It is also reasonable to presume that experiences with bullying in one educational context, such as during primary and/or secondary school, would result, in particular, in feeling social anxiety in other educational contexts such as university.

Having been bullied by peers during one's school days often has long-term associations with the well-being and development of an individual (Aricak 2016; Hawker and Boulton 2000; Pörhölä 2016; Reijntjes et al. 2010). Although the growing body of literature on the relationship between bullying victimization and aspects of well-being has focused on the child and adolescent population, and this research indicates a link between involvement in bullying and physical (e.g., aches and pains; Due et al. 2005; Gini and Pozzoli 2013), psychological (e.g., depression, suicide ideation and self-harm behavior; Reijntjes et al. 2010; Turner et al. 2013; Roland 2002b) and social well-being (e.g., loneliness, withdrawal, peer integration difficulties; Due et al. 2005; Pörhölä 2009; Reijntjes et al. 2010; Schäfer et al. 2004), there are other studies suggesting that these problems can last even into young adulthood (Espelage et al. 2016; Lereya et al. 2015; Meltzer et al. 2011; Newman et al. 2005; Wolke et al. 2013).

Studies also exist to suggest a link between bullying victimization and post-traumatic stress disorder (PTSD; e.g., Espelage et al. 2016). The meta-analysis of this research by Nielsen et al. (2015) shows that bullying is associated with symptoms of post-traumatic stress, but that there is a shortage of clinical and prospective research on that association. Their findings showed that $57 \%$ of victims of bullying report symptom scores for PTSD, which was a much higher percentage than the one for estimated lifetime prevalence of PTSD. The authors argue that, although exposure to bullying constitutes a systematic exposure to a series of negative events over a prolonged time period, rather than one traumatic event, researchers have claimed 
that the distress many of the victims experience equalizes the stress associated with traumatic events.

Together with current or previous exposure to bullying, having these accumulating issues in their well-being can create additional burden on victims' study progress, hamper their integration into the academic community, and consequently increase the level of social anxiety they feel in situations in which they are expected to interact with peers and other members of the academic community in order to prove their skills and knowledge. Although research exists to show that involvement in bullying in any role (i.e., victim, bully, bully-victim) is associated with poorer psychosocial adjustment (i.e., higher levels of health problems, poorer emotional adjustment, and poorer school adjustment; e.g., Nansel et al. 2004), the findings related to the relationship between bullying perpetration and social anxiety are controversial (for reviews, see, Arıcak 2016; Cowie 2013; Cowie et al. 2013). Because the present study focuses on bullying victims' experiences of social anxiety, and due to space limitations, previous literature on the adjustment problems of other groups engaged in bullying is not reviewed here, although they are included in the data analysis.

\section{Methods}

\subsection{Participants and procedures}

In 47 universities, a total of 5086 undergraduate university students participated in the study: $1864(36.6 \%)$ were male $(M=24.7$ years) and $3222(63.4 \%)$ female $(M=23.9$ years $)$. Of the respondents, 2336 (45.9\%) studied at universities of applied sciences (i.e., former polytechnics), and 2750 (54.1\%) at academic universities. To insure a representative national sample, a stratified random sampling method by university was used to identify 9967 students from the overall study population of 282,049 undergraduate students with Finnish citizenship and under the age of 35 years. Of the students recruited for the study, a total of 4984 (46\% males, $54 \%$ females) studied at universities of applied sciences and 4983 (45\% males, 55\% females) studied at academic universities across Finland. The representativeness of the participants was ensured by comparing the sample and respondents with Finnish population statistics (i.e., the Finnish Student Health Service Registry and Statistics Finland; see Students in academic universities statistics, n.d.; Students in universities of applied sciences statistics, n.d.). It was determined that the respondents were representative of the study population in age, university, and field of study; males were slightly underrepresented.

The data for the present research was collected as part of the University Student Health Survey, which is a national survey of Finnish university students designed in collaboration with a multi-disciplinary group of researchers and administered by the Finnish Student Health Service, which provides health care services for all basic degree academic university students in Finland (for a more detailed description, see Kunttu and Huttunen 2009). The study protocol was approved by the Medical Ethics Committee of the Hospital District of South West Finland, and the voluntarily 
participating students gave their informed consent by responding to the questionnaire. The survey was not connected in any way to the course work of students and no extra credit was offered if they decided to participate in it. A postal questionnaire was used, but it was also possible to complete the questionnaire online. Of the completed questionnaires, 3173 were returned by mail and the rest via the Internet.

\subsection{Variables and measures}

The survey questionnaire utilized a variety of scales to measure physical, mental and social health, health behavior, study ability, as well as experiences of bullying. Due to the extensive breadth of the survey, the results are reported in several individual studies by different researchers. The present analysis focuses on students' report of social anxiety and experiences of bullying at school and in higher education.

At the beginning of the questionnaire, participants were asked to provide demographic information. Anxiety was operationalized by means of three types of measures assessing: (a) diagnosed anxiety syndrome that has caused symptoms during the past 12 months, (b) context-specific social anxiety that is experienced across various types of university learning situations, and (c) situation-specific social anxiety that is experienced in particular university learning situations. Experiences of peer bullying and victimization was operationalized by assessing the duration and frequency of exposure to bullying interactions at school and in university. Each variable is described in detail below.

\subsubsection{Bullying and victimization}

Experiences of bullying and victimization were measured retrospectively by asking respondents to describe their recollections of being bullied and bullying others. Since the assessment was based on retrospective self-reports, instead of observations of behaviors from outside, the main focus of the study being on victims, bullying was defined accordingly from victims' perspective to reflect individuals' personal experiences of verbal/nonverbal, relational and physical forms of bullying. Hence, before completing the survey section assessing experiences of bullying and victimization, respondents were provided the definition developed by Pörhölä for the Finnish University Student Health Survey (see, Kunttu and Huttunen 2009): "Bullying refers to a situation in which a student is the object of recurring insult, damage, and/ or discrimination by one or several other students, without being able to influence how she/he is being treated" (translated from Finnish to English for the purpose of this article).

Students' experiences of bullying and victimization in school were then assessed by means of items indicating how long the bullying was experienced ("How much were you bullied when you were at school?"; response range $0-3 ; 0=$ not really at all, $1=$ for some months, $2=$ for about a year, $3=$ for several years), the frequency at which the bullying occurred ("If you think about the times when you were being bullied, how often did this happen?"; response range 0-3;0=I was never bullied, $1=$ occasionally, every now and then, $2=$ weekly, $3=$ daily), and the degree to which 
a participant bullied others ("If you compare yourself to your classmates of that time, how much did you bully other students?"; response range $0-3 ; 0=$ not at all, $1=$ very little, $2=$ relatively much, $3=$ very much). Using the three items, participants were classified into sub-groups labeled victims, bullies, bully-victims, no experience, and inconsistent participants. Victims $(n=498,9.8 \%)$ were classified according to their reported exposure to bullying behavior for the duration of at least one year, at a frequency level of daily to weekly incidents. Bullies $(n=111,2.2 \%)$ were classified according to their self-reported level of bullying others at a frequency of relatively much to very much. Participants were classified as bully-victim $(n=27,0.5 \%)$ if they met the criteria for a victim and a bully. Individuals who reported no experiences with bullying behaviors or victimization were classified as no experience $(n=3557,69.9 \%)$ participants. In addition, a remaining group of participants who either reported unusual instances of exposure to bullying (e.g., long-term exposure to occasional bullying or short-term exposure to frequent bullying; $n=624,12.3 \%$ ), or who had missing values in at least one of the items assessing bullying experiences at school $(n=269,5.3 \%)$, were classified as inconsistent participants and omitted from the analyses because their self-reported experiences did not clearly fit any of the identified groups.

Students' experiences of bullying and victimization at university were assessed by means of two questions ("During your university studies, have you felt that you have been the object of repeated insults, damage, and/or discrimination by one or more students?" and "During your university studies, have you in your opinion repeatedly insulted, damaged, or discriminated some other student or students?"; response range $0-3 ; 0=$ not at all, $1=$ very little, $2=$ relatively much, $3=$ very much). Victims $(n=248,4.9 \%)$ were classified according to their reported exposure to bullying at a frequency level of relatively much or very much. Bullies $(n=57,1.1 \%)$ were classified according to their self-reported level of bullying others at a frequency of relatively much to very much. Respondents were classified as bully-victim $(n=28,0.6 \%)$ if they met the criteria for a victim and a bully, and the remaining group of individuals who reported no experiences with bullying behaviors or victimization at university were classified as no experience $(n=4631,91.1 \%)$ participants. Due to missing values in at least one of the items assessing bullying experiences at university, 122 $(2.4 \%)$ of the respondents could not be classified into any of the groups and were omitted from the analyses.

\subsubsection{Anxiety syndrome and social anxiety}

Students' experiences of anxiety were operationalized by means of two questions. Diagnosed anxiety syndrome was included in a list of health issues by asking: "Has a doctor, dentist, or psychologist diagnosed some permanent, long-term, or recurring illness, health problem, or trauma, which has caused you symptoms or required treatment over the past year (12 months)?" Respondents were then asked to choose each item in the list that was true for them, including "anxiety syndrome (panic attack, fear of social situations, etc.)".

The second question included a set of items assessing the level of social anxiety experienced across various types of university learning situations and is 
called here context-specific social anxiety. The question was presented by asking: "Do you feel such anxiety in your learning situations that it is a problem for you?" and a list of five typical university learning situations was given, consisting of (a) public speaking and presentation situations, (b) seminars, (c) discussing with a teacher or supervisor, (d) speaking in a foreign language, and, (e) exams and tests. These situations were chosen to represent relatively formal learning situations that include evaluation of individual student's performance. The respondents were asked to indicate how much social anxiety they typically felt in each type of learning situation (response range 0-3;0 I feel no anxiety, $1=I$ feel anxiety at times, but it's not a problem, $2=$ anxiety is a slight problem, $3=$ anxiety is a big problem). A total score was calculated for each respondent by averaging across the five items, to indicate the level of context-specific social anxiety (Cronbach's alpha $=.737)$, and scores on individual learning situations were used to indicate the level of situation-specific social anxiety experiences.

\subsubsection{Data analysis}

Data were analyzed using IBM SPSS Statistics software. Since equal variances could not be assumed in the data due to discrepant sample sizes and non-normal distribution of variables, non-parametric tests were used. These are described in more detail when reporting the results.

\section{Results}

\subsection{Experiences of anxiety}

The anxiety syndrome that had caused symptoms during the past 12 months was reported by $158(3.1 \%)$ of the respondents $(n=5078)$. Distribution of the sum-score used to indicate the level of context-specific social anxiety across various types of university learning situations was skewed $(M=.96, S D=.53, n=5044)$, revealing that context-specific social anxiety was experienced by a minority of university students. In the whole sample ( $n$ varying from 4988 to 5039 due to missing values on individual items), the learning situation in which the respondents reported the highest levels of anxiety was public speaking and presentation situations $(M=1.33$, $S D=.79)$, followed by speaking in a foreign language $(M=1.15, S D=.87)$, seminars $(M=1.08, S D=.83)$, and exams and tests $(M=.78, S D=.63)$. The least anxietyinducing situation was discussing with a teacher or supervisor $(M=.45, S D=.62)$. However, significant differences were detected between the groups of victims, bullies, bully-victims, and the no experience group in their experiences of anxiety. In the following sections, these differences are examined by categorizing the respondents first according to their bullying experiences at school, and then, according to their bullying experiences at university. 


\subsection{Bullying at school as categorizing variable}

A Chi square test of independence was performed to examine whether having experiences with bullying in school and having current diagnosis of anxiety syndrome were associated. A significant association $\left(X^{2}[3, n=4185]=37.09, p=.000\right)$ was found. Although an expected number of students in the bully category $(f=3,2.7 \%)$ reported of anxiety syndrome, the number of students in both the victim $(f=33$, $6.6 \%)$ and bully-victim categories $(f=3,11.1 \%)$ who reported this diagnosis was higher than expected, the number of individuals with no experience of bullying at school who reported it was lower than expected $(f=80,2.3 \%)$. Hence, having anxiety syndrome at university was associated with previous exposure to bullying victimization at school, even when victimization had occurred in combination with bullying behavior. It is worth noting, however, that observed and expected counts were less than 5 in both bully and bully-victim categories, which can decrease the reliability of the results regarding these categories.

An independent samples Kruskal-Wallis test was conducted to test whether social anxiety experienced across various types of learning situations in university (i.e., context-specific social anxiety) would vary as a function of having experience with bullying in school. A significant difference was found to exist between groups $\left(X^{2}[3]=9.53, p=.023\right)$. Multiple pairwise comparisons, which were conducted using the Mann-Whitney $U$ test (for which the $p$ value was adjusted using a Bonferroni correction), indicated that the level of social anxiety reported by victimized students $(M=1.03, S D=.58)$ was higher $(U=171.94, p=.016)$ than the anxiety reported by students who had no previous bullying experiences at school $(M=.94$, $S D=.51$ ). Differences between other groups were statistically nonsignificant (see Table 1 for details regarding the multiple comparison tests).

A series of Mann-Whitney $U$ tests were used to examine how the groups of victims, bullies, bully-victims, and students with no experience of bullying differed in the level of anxiety they experienced in different types of learning situations (i.e., situation-specific social anxiety). Statistically significant differences were detected between victims and students with no experience of bullying at school in two types of learning situations. First, compared with those with no experiences of bullying $(M=.42, S D=.59)$, victims reported higher levels of anxiety $(M=.55, S D=.70)$ when discussing with a teacher or supervisor $(U=186.25, p=.001)$. Second, victims reported higher levels of anxiety $(M=1.19, S D=.90)$ than students without experience with bullying $(M=1.06, S D=.82)$ in seminars $(U=143.99, p=.043)$. For

Table 1 Post hoc multiple comparisons of bullying experiences at school with social anxiety in university study situations using Mann-Whitney U tests

\begin{tabular}{lrrrlll}
\hline & \multicolumn{1}{l}{$n$} & $M$ & $S D$ & Bully & Bully-victim & No experience \\
\hline Victim & 498 & 1.03 & .58 & $\mathrm{~ns}$ & $\mathrm{~ns}$ & $p=.016$ \\
Bully & 111 & .94 & .54 & & $\mathrm{~ns}$ & $\mathrm{~ns}$ \\
Bully-victim & 27 & .90 & .66 & & & $\mathrm{~ns}$ \\
No experience & 3548 & .94 & .51 & & & \\
\hline
\end{tabular}


seminars, the level of anxiety reported by the victims was also significantly higher than it was for bully-victims $(M=.78, S D=.93)(U=589.98, p=.044)$. Differences between other groups and across other study situations were nonsignificant.

\subsection{Bullying in university as categorizing variable}

A Chi square test of independence was performed to examine the association between having experiences with bullying at university and having current diagnosis of anxiety syndrome, and a significant association $\left(X^{2}[3, n=4956]=14.60, p=.002\right)$ was found. Anxiety syndrome was reported by a higher than expected number of students in the victim $(f=16,6.5 \%)$, bully $(f=4,7.0 \%)$, and bully-victim roles $(f=2$, $7.1 \%$ ), while the number of students with no experience of bullying at university who reported this diagnosis was lower than expected $(f=132,2.9 \%)$. Hence, having anxiety syndrome was associated with engagement in bullying at university in any role. However, it is worth noting that observed and expected counts were less than 5 in both the bully and bully-victim categories, which can decrease the reliability of the results regarding these student categories.

A Kruskal-Wallis analysis revealed that context-specific social anxiety experienced across various types of learning situations also varied as a function of having experience with bullying at university. A significant difference was found to exist between groups $\left(X^{2}[3]=12.23, p=.007\right)$, with multiple pairwise comparisons indicating that, when compared with students without bullying experiences at university $(M=.95, S D=.52)$, the level of social anxiety in learning situations reported by victimized students $(M=1.09, S D=.60)$ was again significantly higher $(U=311.56$, $p=.005)$, while differences between other groups were statistically nonsignificant (see Table 2 for details regarding the multiple comparison tests).

A series of Mann-Whitney $U$ tests were used to examine how the groups differed in the level of social anxiety they experienced in different types of learning situations. First, in the level of anxiety experienced in seminars, victimized university students $(M=1.28, S D=.91)$ differed significantly from those with no experience of bullying $(M=1.07, S D=.83)(U=293.08, p=.004)$, and, second, compared with students without experiences of bullying $(M=.44, S D=.61)$, victims also reported higher levels of anxiety $(M=.62, S D=.76)$ when discussing with a teacher or supervisor $(U=271.65, p=.004)$. Finally, victims' experiences of anxiety $(M=.91, S D=.66)$ differed from those of the students uninvolved in bullying

Table 2 Post hoc multiple comparisons of bullying experiences at university with social anxiety in university study situations using Mann-Whitney U tests

\begin{tabular}{lrrrrll}
\hline & \multicolumn{1}{c}{$n$} & \multicolumn{1}{c}{$M$} & $S D$ & Bully & Bully-victim & No experience \\
\hline Victim & 247 & 1.09 & .60 & $\mathrm{~ns}$ & $\mathrm{~ns}$ & $p=.005$ \\
Bully & 57 & .99 & .56 & & $\mathrm{~ns}$ & $\mathrm{~ns}$ \\
Bully-victim & 28 & 1.09 & .60 & & & $\mathrm{~ns}$ \\
No experience & 4618 & .95 & .52 & & & \\
\hline
\end{tabular}


$(M=.78, S D=.62)$ for exams and tests $(U=252.44, p=.011)$. Differences between other groups and across other study situations were nonsignificant.

\section{Discussion}

The results of the study indicated that university learning situations cause the highest levels of anxiety to former and current victims of peer bullying. When compared with students with no experience of bullying, victims reported more frequently of having anxiety syndrome and higher levels of context-specific social anxiety across various types of university learning situations, when the respondents were divided into groups using two kinds of categorizing criteria: having bullying experiences at school, and having bullying experiences at university. Learning situations in which the victims of both categories reported significantly higher levels of social anxiety were discussions with a teacher or supervisor and seminars. In addition, students who were victimized at university also reported higher levels of anxiety in tests and exams. Furthermore, the results tentatively suggest that being engaged in bullying while at university might be associated with anxiety syndrome even for bullies and bully-victims. Hence, both short- and long-term associations between bullying experiences and different types of anxiety were detected.

The findings raise the question of what characteristics of the learning situations (seminars, teacher consultations, and tests and exams) aroused more anxiety in the victims than in the students with no experience of bullying. Having the focus on individual performance and learning outcomes and receiving assessment and feedback of these, like in seminars, can be experienced as difficult and sensitive interaction situations by victims of bullying who feel that they have been unvalued and often negatively criticized by peers in learning settings. The fact that bullying victims reported higher social anxiety levels even in learning situations which did not include interaction with fellow students (i.e., teacher consultations, tests and exams), suggests that the generalized and context-specific anxiety that many of them reported covers a wide variety of learning situations in university. Speaking to people in authority is one of the most commonly feared social situations for socially anxious people (Rachman 2013), and for the victims of bullying, having this fear with their teachers could be a sign of an accumulation of social anxiety throughout various interaction situations in university. Teachers at university are influential, hold a central position in defining and manifesting the academic research and learning environment, represent the core of the design and delivery of instruction, and possess key influences on student engagement and learning (Keashly and Wajngurt 2016). For these reasons, even expecting delayed feedback after tests and exams could cause anxiety in students who have recent experiences of being bullied at university and therefore can be sensitive to any criticism.

Given the large sample size, however, the fact that the groups being compared did not differ in the level of social anxiety they reported in public speaking and presentation situations as well as when speaking in a foreign language, was surprising. As regards public speaking and presentation situations, this might, on the one hand, be explained by the fact that this type of communication situation tends to arouse the 
highest levels of anxiety in all students (Almonkari and Kunttu 2012; Russell and Shaw 2009; Topham and Russell 2012). Hence, it is possible that the groups did not differ enough in this learning situation due to the increased levels of anxiety reported by most respondents in the study. On the other hand, as Rachman (2013) suggests, preparing and practicing a speech is a safety behavior that can be most helpful for individuals who suffer from social anxiety. It is possible that careful preparation for interaction situations is a safety behavior preferred by bullying victims whenever it is possible in order to minimize the negative critique they are expecting from their peers. As less spontaneous interaction situations public speaking and presentation situations enable a successful use of this safety behavior. When given the opportunity to have the full attention and their well-prepared message heard by peers who mostly tend to ignore them, victimized students might feel these situations to be rewarding and empowering. Similarly, victims who are skilled at a foreign language could experience the use of that language in classes as a positive challenge rather than an anxiety-inducing situation.

In this study we did not aim at detecting the direction of the association between social anxiety and bullying victimization. As Reijntjes et al. (2010) conclude, internalizing problems such as social anxiety can be a consequence of being victimized as well as it can lead to peer victimization and to maintaining and solidifying an individual's standing as a victim. Whatever this direction is, university students who have problems in their psychosocial well-being related with their current or previous experiences of bullying would benefit from help in recovery. If the victims of bullying also suffer from social anxiety, this would add to their distress and might affect their study success by reducing their participation in academic discussion, disturbing concentration and causing discomfort in learning situations (Almonkari 2017; Almonkari and Kunttu 2012), in addition to increasing loneliness (Due et al. 2005; Reijntjes et al. 2010; Schäfer et al. 2004), dissociation (Arseneault et al. 2010; Newman et al. 2005), and causing peer integration difficulties (Pörhölä 2009; Russell and Topham 2012; Schäfer et al. 2004; Wolke et al. 2013), which are typical problems for bullying victims. The avoidant behavior of a socially anxious student who has also been bullied could easily be misunderstood or misinterpreted. The student could be regarded as shy, unwilling to learn, lazy, or even as arrogant.

Therefore, identification of social anxiety and early intervention in bullying would be beneficial to students who suffer from these problems. However, as Topham and Russell (2012) state, social anxiety is a hidden disability, and it can therefore be difficult to identify. Yet identification of these problems would be important because many students feel unable or unwilling to seek help. They may be concerned that their problems would not be taken seriously or they may have a fear of stigmatization. For example, in the study by Russell and Topham (2012), less than 1 out of 5 socially anxious students reported seeking help from their personal tutor or student counselor. In Finland, 12.3\% of university students anonymously reported a wish to receive support and help with their social anxiety problems (Kunttu and Pesonen 2013).

The pedagogical staff, study counselors, and health care professionals should learn to identify those students who need special help in their studies due to having these experiences. Teaching staff might want to learn means to help these students 
cope with the anxiety they face in learning situations. Teachers would also benefit from learning how to bring up their concerns regarding the behavior and experience of particular students in learning situations, how to give feedback to them in an encouraging way, and how to help these students better integrate with their fellow students. Teachers could purposefully aim at creating a safe learning atmosphere, where the focus would be on learning, instead of on performance or criticism of learning outcomes. Many students could be helped to cope with stressful learning situations by providing social-emotional guidance for their studies; offering special courses for practicing their interaction skills; and organizing comprehensive student health services. Getting assistance with their study skills, such as identifying the characteristics and demands of academic narratives and choosing effective interaction strategies would be useful particularly for students who feel anxiety in exams and tests. There is also a strong need for multiprofessional cooperation, information exchange, and dialogue between students, teaching staff and health care professionals to develop means to promote the study success and well-being of university students.

\section{Limitations and suggestions for future research}

The present study has certain limitations that can be improved in future research. First, although the respondents were representative of the study population with respect to age, university, and field of study, with males being slightly underrepresented, caution must be taken when generalizing the results beyond university students who may or may not differ from other young adults. Future studies would benefit from including young adults and adults from various educational institutes and working life, to examine whether victims of bullying feel more social anxiety in learning situations in any social context. Cultural differences may also occur and should be examined.

Second, the assessment of social anxiety as well as engagement in bullying and victimization were based on self-reports, thus indicating respondents' personal experiences and recollections of these matters. No medical certificates, expert observations, peer evaluations, or other documents were used. Hence, when evaluating the reliability of the results we cannot be sure whether or not the same respondents would be regarded as socially anxious or as having been in a particular bullying role, for example, by their teachers, peers, or health care professionals, and future studies would definitely benefit from using various assessment methods. However, one could presume that when we are examining associations between people's life events and well-being, individuals' own experiences would be the most important indicators in determining these factors. If a person feels that he or she has been victimized or has felt social anxiety, then these experiences are meaningful to that person and determine his or her reality.

Third, even though we used a sample of over 5000 respondents, the number of bully-victims (i.e., individuals in dual roles) remained small and supported the use of non-parametric tests to obtain reliable group comparisons. Future studies could solve this problem by using even larger sample sizes to examine whether this 
particular group succeeds in recovering from their bullying experiences faster and better than victims do, even though they have been found to suffer from the most severe problems in their well-being during their school days (Houbre et al. 2006; Perren et al. 2010; Roland 2002a; Woods and White 2005). Finally, as the number of students categorized as inconsistent participants was quite high, future studies could examine this kind of participant category in more detail, in order to identify possible subgroups within the category, and examine their problems.

Acknowledgements Open access funding was provided by University of Eastern Finland (UEF) including Kuopio University Hospital.

Funding The data collection for this research was supported by the Ministry of Education and Culture, Finnish Student Health Service, and University of Applied Sciences Students in Finland.

\section{Compliance with ethical standards}

Conflict of interest The authors declare that they have no conflict of interest.

Open Access This article is distributed under the terms of the Creative Commons Attribution 4.0 International License (http://creativecommons.org/licenses/by/4.0/), which permits unrestricted use, distribution, and reproduction in any medium, provided you give appropriate credit to the original author(s) and the source, provide a link to the Creative Commons license, and indicate if changes were made.

\section{References}

Almonkari, M. (2007). Jännittäminen opiskelun puheviestintätilanteissa [Social anxiety in studyrelated communication situations] (Jyväskylä Studies in Humanities, 86). Jyväskylä: University of Jyväskylä.

Almonkari, M. (2017). Sosiaalinen jännittäminen opiskelutilanteissa [Social anxiety in study situations] (updated 5.6.2017). In K. Kunttu, A. Komulainen, K. Makkonen, \& P. Pynnönen, (Eds.), Opiskeluterveys [online version]. Helsinki, Finland: Kustannus Oy Duodecim. Retrieved December 3, 2017, from http://www.oppiportti.fi/ote00045 (available with user name).

Almonkari, M., \& Kunttu, K. (2012). Korkeakouluopiskelijoiden jännittämiskokemusten yhteys opiskelukykyyn [Social anxiety and study ability among higher education students]. In M. Valo, A. Sivunen, L. Mikkola, \& V. Laaksonen (Eds.), Prologi, Puheviestinnän vuosikirja 2012 (pp. 7-27). Jyväskylä: Prologos ry.

Arıcak, O. T. (2016). The relationship between mental health and bullying. In H. Cowie \& C.-A. Myers (Eds.), Bullying among university students: cross-national perspectives (pp. 76-90). Abingdon: Routledge.

Arseneault, L., Bowes, L., \& Shakoor, S. (2010). Bullying victimization in youths and mental health problems: 'Much ado about nothing'? Psychological Medicine, 40, 717-729.

Bond, L., Carlin, J. B., Thomas, L., Rubin, K., \& Patton, G. (2001). Does bullying cause emotional problems? A prospective study of young teenagers. BMJ, 323, 480-484.

Clark, D. M., \& Wells, A. (1995). A cognitive model of social phobia. In D. M. Clark \& A. Wells (Eds.), Social phobia: Diagnosis, assessment and treatment. New York: Guilford.

Cooper, J. R. M., Walker, J., Askew, R., Robinson, J. C., \& McNair, M. (2011). Students' perceptions of bullying behaviours by nursing faculty. Issues In Educational Research, 21, 1-21.

Copeland, W. E., Wolke, D., Angold, A., \& Costello, E. J. (2013). Adult psychiatric outcomes of bullying and being bullied by peers in childhood and adolescence. JAMA Psychiatry, 70, 419-426.

Cowie, H. (2013). The immediate and long-term effects of bullying. In I. Rivers \& N. Duncan (Eds.), Bullying: Experiences and discourses of sexuality and gender (pp. 10-18). New York: Routledge. 
Cowie, H., Bauman, S., Coyne, I., Myers, C.-A., Pörhölä, M., \& Almeida, A. (2013). Cyberbullying amongst university students: An emergent cause for concern? In P. K. Smith \& G. Steffgen (Eds.), Cyberbullying through the new media (pp. 165-177). London: Psychology Press.

Diagnostic and Statistical Manual of Mental Disorders (DSM-5; 5th ed.). (2013). Washington, DC: The American Psychiatric Association.

Due, P., Holstein, B. E., Lynch, J., Diderichsen, F., Gabhain, S. N., Scheidt, P., et al. (2005). Bullying and symptoms among school-aged children: International comparative cross-sectional study in 28 countries. European Journal of Public Health, 15(2), 128-132.

Espelage, D. L., Hong, J. S., \& Mebane, S. (2016). Recollections of childhood bullying and multiple forms of victimization: Correlates with psychological functioning among college students. Social Psychology of Education, 19(4), 715-728.

Espelage, D. L., Hong, J. S., Rao, M. A., \& Low, S. (2013). Associations between peer victimization and academic performance. Theory into Practice, 52(4), 233-240. https://doi.org/10.1080/00405 841.2013.829724.

Feldman, M. A., Ojanen, T., Gesten, E. L., Smith-Schrandt, H., Brannick, M., Totura, C. M. W., et al. (2014). The effects of middle school bullying and victimization on adjustment through high school: Growth modeling of achievement, school attendance, and disciplinary trajectories. Psychology in the Schools, 51, 1046-1062.

Gini, G., \& Pozzoli, T. (2013). Bullied children and psychosomatic problems: A meta-analysis. Pediatrics, 132, 720-729. https://doi.org/10.1542/peds.2013-0614.

Giovazolias, T., \& Malikiosi-Loizos, M. (2016). Bullying at Greek universities: An empirical study. In H. Cowie \& C.-A. Myers (Eds.), Bullying among university students: cross-national perspectives (pp. 110-126). London: Routledge.

Gladden, R. M., Vivolo-Kantor, A. M., Hamburger, M. E., \& Lumpkin, C. D. (2014). Bullying surveillance among youths: Uniform definitions for public health and recommended data elements (version 1.0.). Atlanta, GA: National Center for Injury Prevention and Control, Centers for Disease Control and Prevention and U.S. Department of Education.

Glew, G. M., Fan, M.-Y., Katon, W., Rivara, F. P., \& Kernic, M. A. (2005). Bullying, psychosocial adjustment, and academic performance in elementary school. Archives of Pediatrics and Adolescent Medicine, 159, 1026-1031.

Gómez-Ortiz, O., Roldán, R., Ortega-Ruiz, R., \& García-López, L.-J. (2017). Social anxiety and psychosocial adjustment in adolescents: Relation with peer victimization, self-esteem and emotion regulation. Child Indicators Research. https://doi.org/10.1007/s12187-017-9506-3.

Hawker, D. S. J., \& Boulton, M. J. (2000). Twenty years' research on peer victimization and psychosocial maladjustment: A meta-analytic review of cross-sectional studies. Journal of Child Psychology and Psychiatry and Allied Disciplines, 41, 441-455.

Holt, M. K., Greif Green, J., Reid, G., DiMeo, A., Espelage, D. L., Felix, E. D., et al. (2014). Associations between past bullying experiences and psychosocial and academic functioning among college students. Journal of American College Health, 62(8), 552-560. https://doi.org/10.1080/07448 481.2014.947990.

Houbre, B., Tarquinio, C., Thuillier, I., \& Hergott, E. (2006). Bullying among students and its consequences on health. European Journal of Psychology of Education, 21, 183-208.

Juvonen, J., Nishina, A., \& Graham, S. (2000). Peer harassment, psychological adjustment, and school functioning in early adolescence. Journal of Educational Psychology, 92, 349-359.

Juvonen, J., Wang, Y., \& Espinoza, G. (2011). Bullying experiences and compromised academic performance across middle school grades. The Journal of Early Adolescence, 31(1), 152-173.

Keashly, L., \& Wajngurt, C. (2016). Faculty bullying in higher education. Psychology and Education, 53, 79-90.

Kunttu, K., \& Huttunen, T. (2009). Student Health Survey 2008: A national survey among Finnish university students (Research publications, 45). Helsinki, Finland: Finnish Student Health Service. Retrieved February 4, 2018, from http://www.yths.fi/en/health_information_and_research/resea rch_and_publications/the_finnish_student_health_survey.

Kunttu, K., \& Pesonen, T. (2013). Student Health Survey 2012: A national survey among Finnish university students (Research publications, 47). Helsinki, Finland: Finnish Student Health Service. Retrieved January 12, 2018, from http://www.yths.fi/filebank/2263-KOTT2012_in_English.pdf.

Lereya, S. T., Copeland, W. E., Costello, E. J., \& Wolke, D. (2015). Adult mental health consequences of peer bullying and maltreatment in childhood: Two cohorts in two countries. Lancet Psychiatry, 2, 524-531. https://doi.org/10.1016/S2215-0366(15)00165-0. 
Lund, E. M., \& Ross, S. W. (2016). Bullying perpetration, victimization, and demographic differences in college students: A review of the literature. Trauma, Violence, \& Abuse, 18, 348-360. https://doi. org/10.1177/1524838015620818.

Marraccini, M. E., Weyandt, L. L., \& Rossi, J. S. (2015). College students' perceptions of professor/ instructor bullying: Questionnaire development and psychometric properties. Journal of American College Health, 63, 563-572. https://doi.org/10.1080/07448481.2015.1060596.

Matsunaga, M. (2010). Individual dispositions and interpersonal concerns underlying bullied victims' self-disclosure in Japan and the US. Journal of Social \& Personal Relationships, 27, 1124-1148. https://doi.org/10.1177/0265407510380084.

Meltzer, H., Vostanis, P., Ford, T., Bebbington, P., \& Dennis, M. S. (2011). Victims of bullying in childhood and suicide attempts in adulthood. European Psychiatry, 26, 498-503.

Menesini, E., \& Salmivalli, C. (2017). Bullying in schools: The state of knowledge and effective interventions. Psychology, Health \& Medicine. https://doi.org/10.1080/13548506.2017.1279740.

Nansel, T. R., Craig, W., Overpeck, M. D., Saluja, G., Ruan, W. J., \& the HBSC Bullying Analyses Working Group. (2004). Cross-national consistency in the relationship between bullying behaviors and psychosocial adjustment. Archives of Pediatrics and Adolescent Medicine, 158(8), 730736. https://doi.org/10.1001/archpedi.158.8.730.

Newman, M. L., Holden, G. W., \& Delville, Y. (2005). Isolation and the stress of being bullied. Journal of Adolescence, 28(3), 343-357.

Nielsen, M. B., Tangen, T., Idsoe, T., Matthiesen, S. B., \& Mageroy, N. (2015). Post-traumatic stress disorder as a consequence of bullying at work and at school. A literature review and meta-analysis. Aggression and Violent Behavior, 21, 17-24.

Olweus, D. (1993). Bullying at school: What do we know and what can we do. Oxford: Blackwell.

Pabian, S., \& Vandebosch, H. (2016). An investigation of short-term longitudinal associations between social anxiety and victimization and perpetration of traditional bullying and cyberbullying. Journal of Youth and Adolescence, 45, 328-339.

Parpala, A., \& Lindblom-Ylänne, S. (2007). University teachers' conception of good teaching in the units of high quality education. Studies in Educational Evaluation, 33, 355-370.

Perren, S., Dooley, J., Shaw, T., \& Cross, D. (2010). Bullying in school and cyberspace: Associations with depressive symptoms in Swiss and Australian adolescents. Child and Adolescent Psychiatry and Mental Health, 4(28). Retrieved May 6, 2017, from http://www.capmh.com/content/4/1/28.

Pörhölä, M. (2009). Psychosocial well-being of victimized students. In T. A. Kinney \& M. Pörhölä (Eds.), Anti and pro-social communication: Theories, methods, and applications (pp. 83-93). New York: Peter Lang.

Pörhölä, M. (2016). Do the roles of bully and victim remain stable from school to university? Theoretical considerations. In H. Cowie \& C.-A. Myers (Eds.), Bullying among university students: Cross-national perspectives (pp. 35-46). Abingdon: Routledge.

Pörhölä, M., Cvancara, K., Kaal, E., Tampere, K., \& Torres, B. (2016). Cross-cultural comparisons of bullying among university students: Perspectives from Argentina, Estonia, Finland and the United States. In H. Cowie \& C.-A. Myers (Eds.), Bullying among university students: Crossnational perspectives (pp. 127-142). Abingdon: Routledge.

Pörhölä, M., Karhunen, S., \& Rainivaara, S. (2006). Bullying at school and in the workplace: A challenge for communication research. In C. S. Beck (Ed.), Communication yearbook 30 (pp. 249301). Mahwah, NJ: Erlbaum.

Rachman, S. (2013). Anxiety (3rd ed.). London: Psychology Press.

Reijntjes, A., Kamphuis, J. H., Prinzie, P., \& Telch, M. J. (2010). Peer victimization and internalizing problems in children: A meta-analysis of longitudinal studies. Child Abuse and Neglect, 34(4), 244-252.

Roland, E. (2002a). Aggression, depression and bullying others. Aggressive Behavior, 28, 198-206.

Roland, E. (2002b). Bullying, depressive symptoms and suicidal thoughts. Educational Research, 44, 55-67.

Rospenda, K. M., Richman, J. A., Wolff, J. M., \& Burke, L. A. (2013). Bullying victimization among college students: Negative consequences for alcohol use. Journal of Addictive Diseases, 32, 325342. https://doi.org/10.1080/10550887.2013.849971.

Russell, G., \& Shaw, S. (2009). A study to investigate the prevalence of social anxiety in a sample of higher education students in the United Kingdom. Journal of Mental Health, 18(3), 198-206.

Russell, G., \& Topham, P. (2012). The impact of social anxiety on student learning and well-being in higher education. Journal of Mental Health, 21(4), 375-385. 
Saarinen, P. (2016). Korkeakoulukiusaamisen yhteys opiskelijan opiskelukykyyn ja opintomenestykseen [Association between bullying at university and student's study ability and achievements] (Master's thesis, University of Jyväskylä, Finland). Retrieved February 3, 2018, from http://urn.fi/URN:NBN:fi:jyu-201604062019.

Schäfer, M., Korn, S., Smith, P. K., Hunter, S. C., Mora-Merchán, J. A., Singer, M. M., et al. (2004). Lonely in the crowd: Recollections of bullying. British Journal of Developmental Psychology, 22, 379-394.

Schlenker, B. R., \& Leary, M. R. (1982). Social anxiety and self-presentation: A conceptualization and model. Psychological Bulletin, 92, 641-669.

Stapinski, L. A., Araya, R., Heron, J., Montgomery, A. A., \& Stallard, P. (2015). Peer victimization during adolescence: Concurrent and prospective impact on symptoms of depression and anxiety. Anxiety, Stress and Coping, 28(1), 105-120. https://doi.org/10.1080/10615806.2014.962023.

Storch, E. A., Brassard, M. R., \& Masia-Warner, C. L. (2003). The relationship of peer victimization to social anxiety and loneliness in adolescence. Child Study Journal, 33, 1-18.

Storch, E. A., \& Masia-Warner, C. L. (2004). The relationship of peer victimization to social anxiety and loneliness in adolescent females. Journal of Adolescence, 27, 351-362.

Strøm, I. F., Thoresen, S., Wentzel-Larsen, T., \& Dyb, G. (2013). Violence, bullying and academic achievement: A study of 15-year-old adolescents and their school environment. Child Abuse and Neglect, 37(4), 243-251. https://doi.org/10.1016/j.chiabu.2012.10.010.

Students in academic universities statistics. (n.d.). Retrieved December 6, 2017, from http://www.stat.fi/ til/yop/2007/index.html.

Students in universities of applied sciences statistics. (n.d.). Retrieved December 6, 2017, from http:// www.stat.fi/til/akop/2007/index.html.

Topham, P., \& Russell, G. (2012). Social anxiety in higher education. The Psychologist, 25(4), $280-282$.

Turner, M. G., Exum, M. L., Brame, R., \& Holt, T. J. (2013). Bullying victimization and adolescent mental health: General and typological effects across sex. Journal of Criminal Justice, 41(1), 53-59.

Volk, A. A., Dane, A. V., \& Marini, Z. A. (2014). What is bullying? A theoretical redefinition. Developmental Review, 34, 327-343.

Wensley, K., \& Campbell, M. A. (2012). Heterosexual and nonheterosexual young university students' involvement in traditional and cyber forms of bullying. Cyberpsychology, Behavior \& Social Networking, 15, 649-654. https://doi.org/10.1089/cyber.2012.0132.

Wolke, D., Copeland, W. E., Angold, A., \& Costello, E. J. (2013). Impact of bullying in childhood on adult health, wealth, crime, and social outcomes. Psychological Science, 24, 1958-1970.

Woods, S., \& White, E. (2005). The association between bullying behaviour, arousal levels and behaviour problems. Journal of Adolescence, 28, 381-395.

Publisher's Note Springer Nature remains neutral with regard to jurisdictional claims in published maps and institutional affiliations.

Maili Pörhölä Ph.D., is an adjunct professor in the School of Humanities at the University of Eastern Finland. She has a background in communication research and her interests include bullying and abuse in social relationships from school to higher education and workplaces and their associations with psychosocial well-being.

Merja Almonkari Ph.D., has worked as a senior lecturer at the Language Centre, University of Jyväskylä, Finland. Her research interests include social anxiety and pedagogical development of communication courses for academic purposes.

Kristina Kunttu M.D., Ph.D., adjunct professor, is a senior researcher in the Finnish Student Health Service (FSHS). She has been the principal investigator in the University Student Health surveys. She is also a general practitioner in FSHS. In her research she focuses on the well-being issues of university students. 